\title{
Business Intelligence for Paintball Tournament Matchmaking Using Particle Swarm Optimization
}

\author{
M.T. Mishan", A.F.A. Fadzil ${ }^{2}$, K.A.F.A. Samah ${ }^{3}$, N.F. Baharin ${ }^{4}$, N. Anuar ${ }^{5}$ \\ ${ }^{1,2,3,4}$ Faculty of Computer and Mathematical Sciences, Universiti Teknologi MARA (Kampus Jasin), \\ 77300 Merlimau, Melaka, Malaysia \\ ${ }^{5}$ Foundation Centre UiTM, Universiti Teknologi MARA (Puncak Alam), Selangor, Malaysia
}

\begin{tabular}{l} 
Article Info \\
\hline Article history: \\
Received Mar 3, 2018 \\
Revised Apr 11, 2018 \\
Accepted Apr 21, 2018 \\
\hline
\end{tabular}

Keywords:

Intelligent paintball tournament Matchmaking Particle Swarm Optimization Convergence

\begin{abstract}
Paintball has gained a huge popularity in Malaysia with growing number of tournaments organized nationwide. Currently, Ideal Pro Event, one of the paintball organizer found difficulties to pair a suitable opponent to against one another in a tournament. This is largely due to the manual matchmaking method that only randomly matches one team with another. Consequently, it is crucial to ensure a balanced tournament bracket where eventual winners and losers not facing one another in the very first round. This study proposes an intelligent matchmaking using Particle Swarm Optimization (PSO) and tournament management system for paintball organizers. PSO is a swarm intelligence algorithm that optimizes problems by gradually improving its current solutions, therefore countenancing the tournament bracket to be continually improved until the best is produced. Indirectly, through the development of the system, it is consider as an intelligence business idea since it able to save time and enhance the company productivity. This algorithm has been tested using 3 size of population; 100, 1000 and 10,000. As a result, the speed of convergence is consistent and has not been affected through big population.
\end{abstract}

Copyright (C) 2018 Institute of Advanced Engineering and Science. All rights reserved.

\section{Corresponding Author:}

M.T. Mishan,

Faculty of Computer and Mathematical Sciences,

Universiti Teknologi MARA (Kampus Jasin),

77300 Merlimau, Melaka, Malaysia.

Email: mtaufik@melaka.uitm.edu.my

\section{INTRODUCTION}

Nowadays, in order to cope with the complexity and sustainly maintain a competitive business, several management practices have been developed and designed. Business intelligence (BI) is one of the effective and innovative strategic management. It referring to the technologies, integration of business information with the main purposes to support better business decision making. In today's dynamic business environment, it is important to have an effective system to avoid uncertainty [1].

Paintball is a game that eliminates opponents by shooting them with color filled, breakable and vegetable oil or in other word is pellets [2]. The pallets are usually shot from a paintball gun. The pallet being power by a compressed air that been compress from 1500psi up to 4500psi. The game can be played in outdoor or indoor fields with the various of size. There are various gameplay that can be played in paintball, such as Woodsball, Scenario, Speedball, and Strategy [3]. The field is full of the natural or artificial terrain. The terrain using for tactical cover. There are also many types of rule that can be played in paintball, for example, elimination, capturing objects, capture the flag, ammunition limits, defending or attacking a particular point. The duration of the game is depending on the player, in which it can last from seconds to hours, or even days in scenario play [4]. Paintball players are divided into multiple divisions; professional, semi-professional, division 1, division 2, division 3, and division 4. The Paintball Asia League Series 
(PALS), headquartered in Petaling Jaya near the capital city of Kuala Lumpur organizes tournaments and events around the asian region. The Paintball World Cup Asia, held annually in Langkawi Island [5] is one of the major tournament event currently being organized in Malaysia.

However, Ideal Pro Event, a paintball organizer has difficulties in managing the paintball tournament specifically in terms of creating the matchmaking tournament bracket. According to a survey conducted towards 45 respondents that encompasses of professional paintball players and organizers in Melaka, 91\% of respondents indicated that they find it difficult to manage paintball tournament due to the coach or organizer still employing the traditional pen and paper methods. They are also admitted to employ the use of Microsoft Excel to store the tournament-related data. Creating the matchmaking bracket therefore largely involves the element of luck due to its randomness. The manual matchmaking was not optimized and may put an eventual tournament winner with the runner-up in the very first round. Creating an optimized tournament matchmaking bracket presents a very large challenge especially when considering a large number of participants. This paper therefore presents an intelligent paintball tournament matchmaking using evolutionary-based swarm intelligence optimization algorithm; the particle swarm optimization (PSO) algorithm.

Preliminarily, there were three potential evolutionary-based swarm intelligence optimization algorithm that are considered to be employed in this paper; PSO, Artificial Bee Colony (ABC), and Ant Colony Optimization (ACO). Table 1 illustrates the advantages and disadvantages of the algorithm technique.

Table 1. Advantages and Disadvantages of the Algorithm Technique

\begin{tabular}{|c|c|c|c|c|}
\hline Algorithm Technique & Year & Behavior & Advantages & Disadvantages \\
\hline $\begin{array}{l}\text { Particle Swarm } \\
\text { Optimization }\end{array}$ & 1995 & $\begin{array}{l}\text { Bird } \\
\text { Flocking or } \\
\text { fish } \\
\text { schooling }\end{array}$ & $\begin{array}{l}\text { - Easy to implement } \\
\text { - Follow the best particle and } \\
\text { try to improve itself } \\
\text { - Flexible in many ways } \\
\text { - Very fast convergence }\end{array}$ & $\begin{array}{l}\text { - Easy to fall into local optimum } \\
\text { in high-dimensional space } \\
\text { - Low convergence rate }\end{array}$ \\
\hline Artificial Bee Colony & 2005 & $\begin{array}{l}\text { Honeybee } \\
\text { swarm }\end{array}$ & $\begin{array}{l}\text { - Self-organizing } \\
\text { - Collective intelligent data }\end{array}$ & $\begin{array}{l}\text { - Abandoning poor solution } \\
\text { - Poor local search ability }\end{array}$ \\
\hline $\begin{array}{l}\text { Ant Colony } \\
\text { Optimization }\end{array}$ & 1992 & Ants colony & $\begin{array}{l}\text { - Efficient for traveling } \\
\text { salesman problem } \\
\text { - Inherent parallelism }\end{array}$ & $\begin{array}{l}\text { - Sequence of random decisions } \\
\text { - Theoretical analysis is difficult }\end{array}$ \\
\hline
\end{tabular}

PSO was first intended for simulating social behaviour towards the movement of organisms in a bird flock or fish school [6]. PSO has been chosen because it was the most effective with its ease of implementation and its nature of fast convergence. It can be used and optimize to search every large space of particle solution [7-8]. This proven that PSO has been successfully applied in many research and application areas in past several years with better results, faster and cheaper [9]. In this study, PSO calculates it fitness value for each particle and compare the value [10]. Figure 1 reveals the flow diagram for the PSO algorithm.

To optimize a solution, it first initializes each particle in the population. The algorithm then calculates the fitness value of each particles within the population. Then PSO randomly picks any particle to set it as particle best (pBest). After that, it compares the pBest with another particle. If the current particle fitness value is greater than pBest, it assigns that current fitness into new pBest. If the current fitness is less than the pBest, it keeps the previous pBest. After comparing the fitness value, the pBest value be assigned to global Best (gBest) in another word it become the population best fitness value to guide the entire population [8]. Then it calculates the velocity for each particle and use it to update its data values. Lastly, it identifies if the target or maximum epochs reached. If not, it repeats by calculating the fitness of each particle and so on. If it reached the target or maximum, the search stops at that point only.

The remainder of this paper is organized as follows. In Section 2, the research material and method used are discussed in detail. Section 3 presents the results and analysis of the testing results. Finally, Section 4 summarizes the conclusion and future work. 


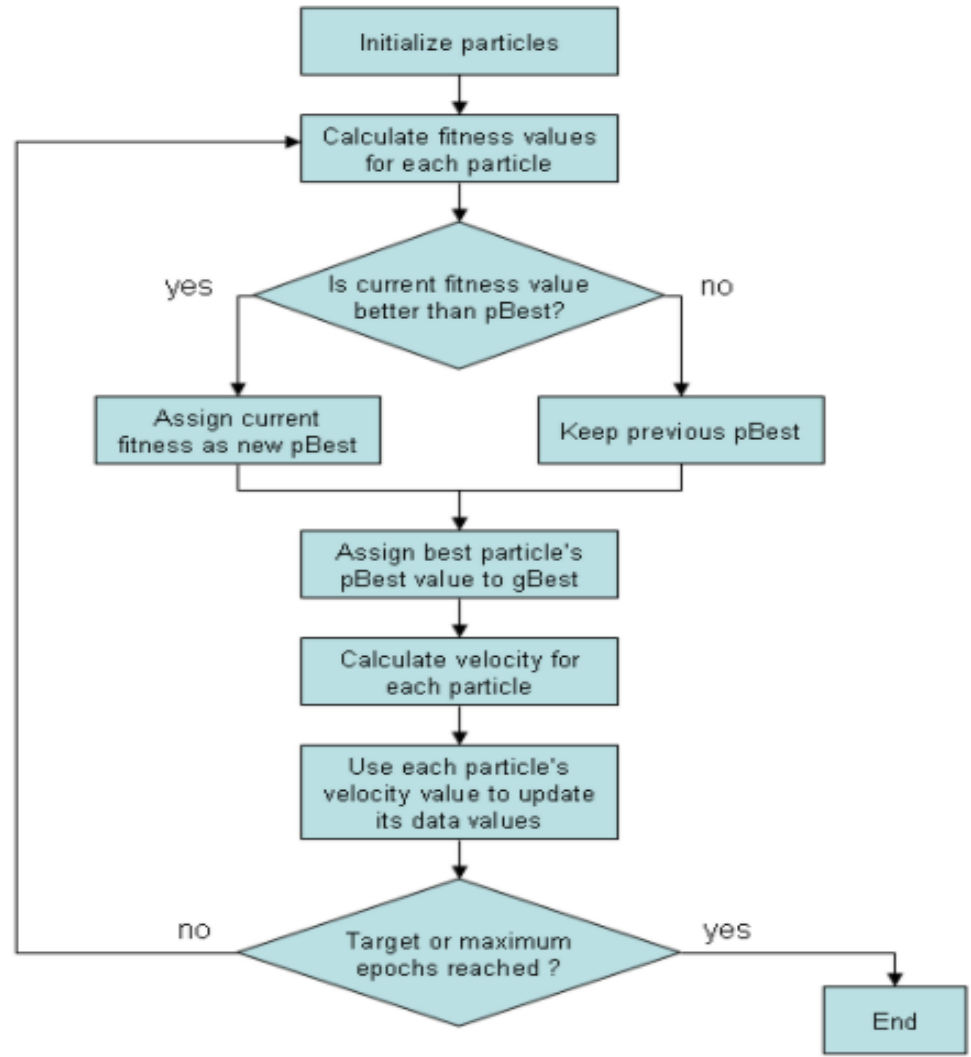

Figure 1. Flow Diagram Illustrating the Particle Swarm Optimization

\section{RESEARCH MATERIAL AND METHOD}

In this study, the research methods are divided into three parts which are the algorithm design using PSO, system workflow and web-based system interface design.

\subsection{Algorithm Design using PSO}

Step 1: Initialize the particle in the population. Tournament brackets are initialized by randomly selecting different teams in the database as in Figure 2 to form an arbitrary sequence (tournament bracket).

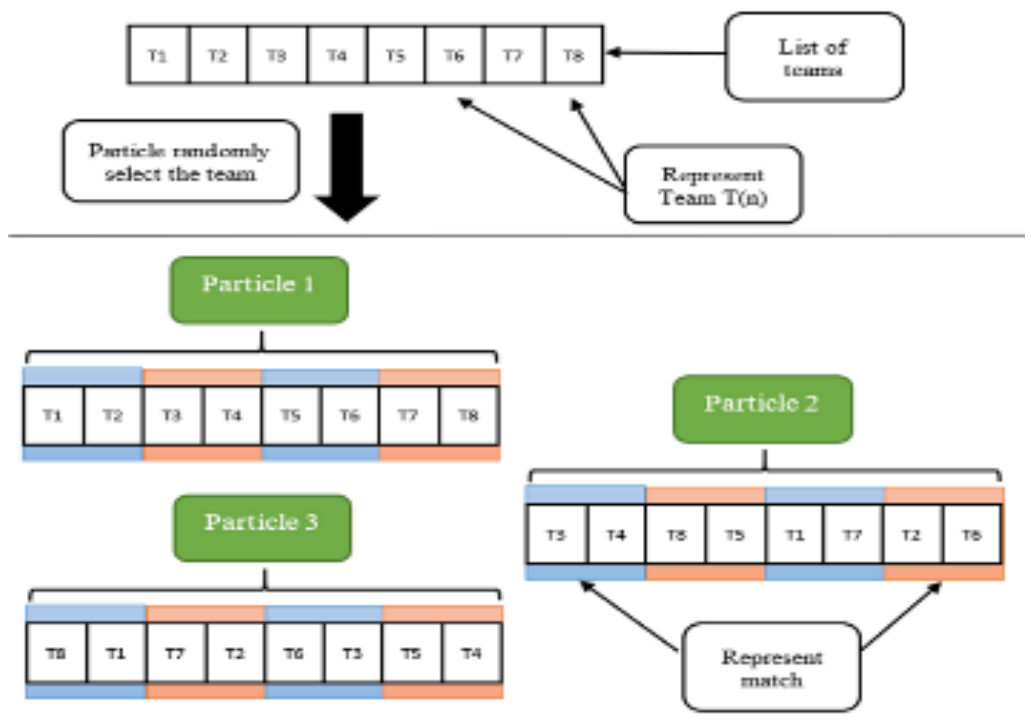

Figure 2. Initialize Particle by Randomly Selecting the Team 
Step 2: Calculate fitness for each particle (tournament bracket) using each player's point. Figure 3 illustrates the fitness function by comparing points available from the particle. The value of fitness for each particle are totalled up and initialized as pBest as shown in Figure 4.

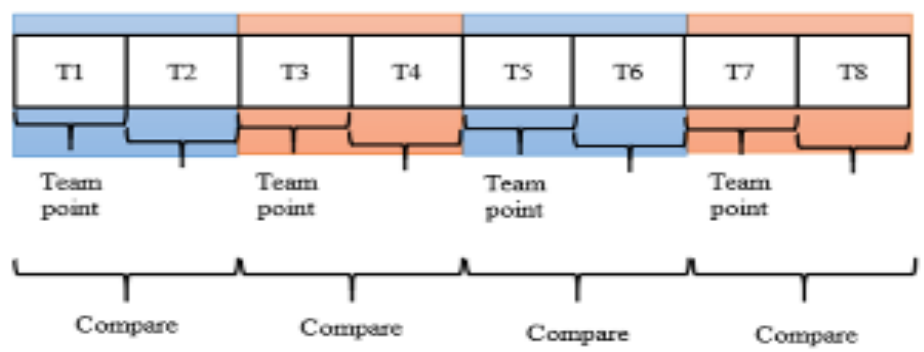

Figure 3. Comparing Team Point

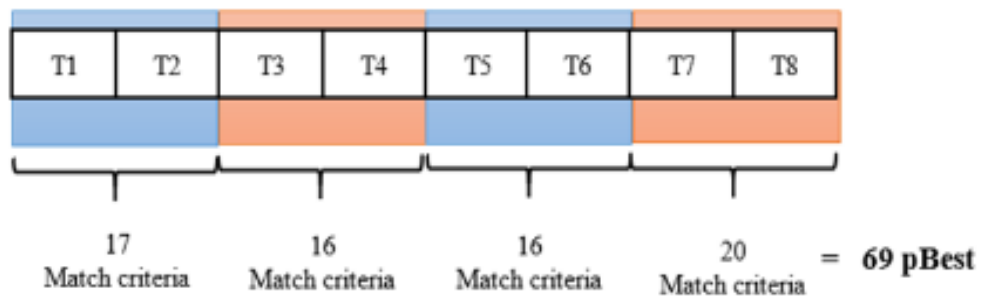

Figure 4. Find Personal Best (pBest)

Step 3: The fittest particle are then assigned as the gBest. The algorithm find the pBest with the highest fitness value to become the gBest in the population as shown in Figure 5 (pBest being assign to gBest).
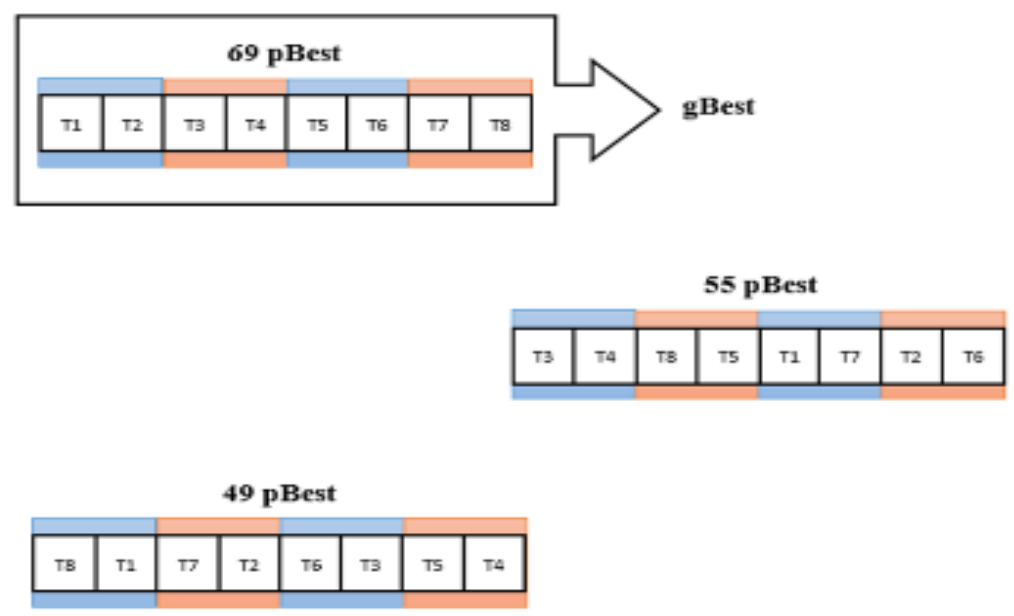

Figure 5. Find the Global Best (gBest)

Step 4: Calculate Velocity. The algorithm then calculates the velocity between different particle's fitness values. This determine how much a particle need to follow the best particle in order to improve its fitness value. The higher the velocity, the more it need to follow the best particle. Figure 6 shows a better view of this phase. 


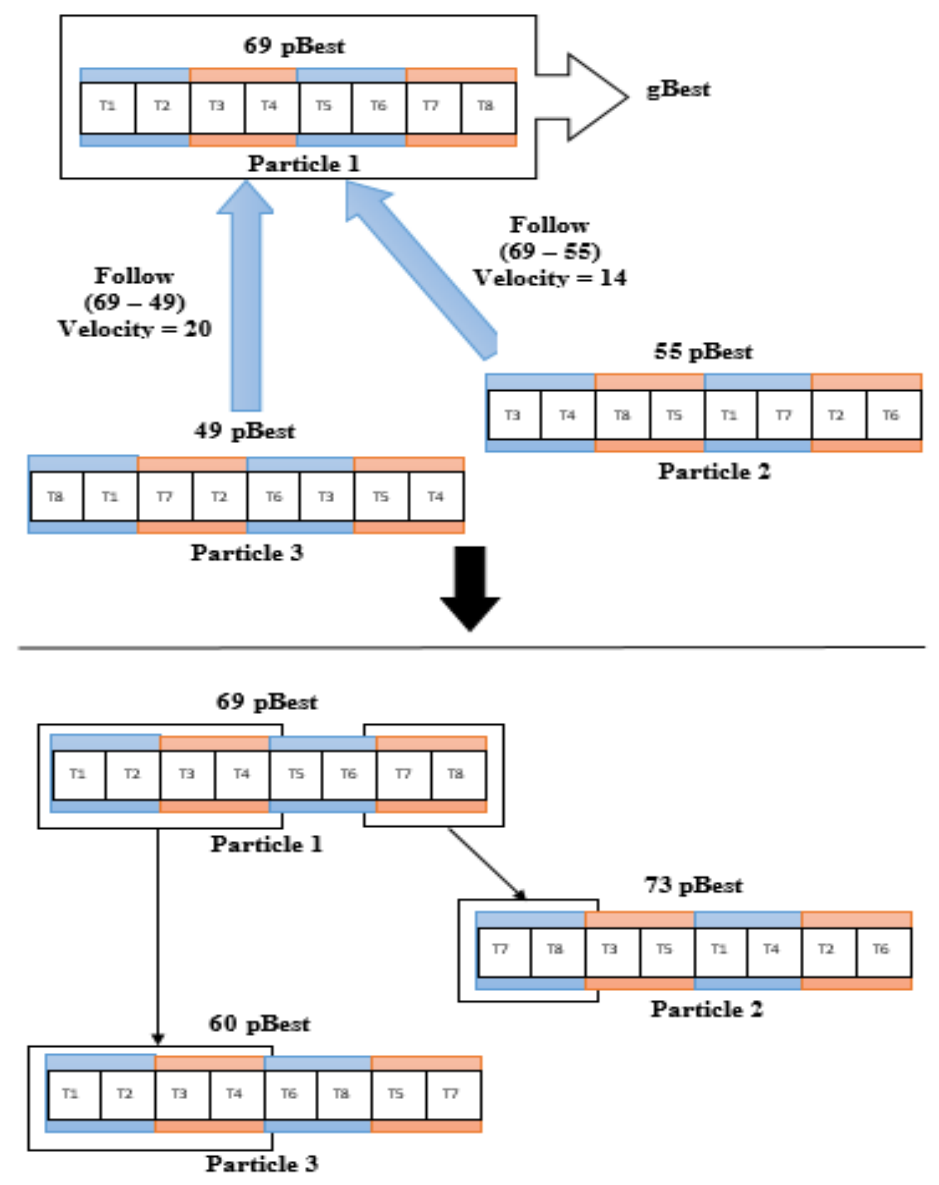

Figure 6. Velocity Calculation

Step 5: Update Data and New gBest. The new pBest value are updated as the particle follows the gBest particle. Thus, the new gBest will also be updated if the pBest fitness value of the any particle surpasses the current gBest particle. Figure 7 illustrates the process of updating the new gBest and how subsequent particles follows the new leader.

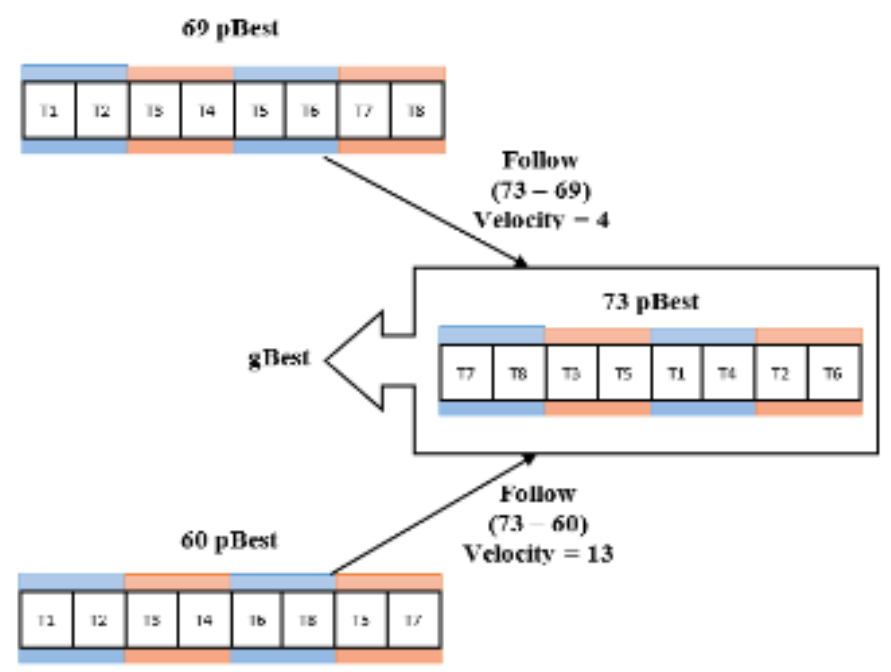

Figure 7. Update the New gBest 
Step 6: Repeat Step. Lastly, it repeats the entire step from step 2 to 5 until there is no possible gBest that can improve upon the current gBest in the population.

\subsection{System Workflow}

Figure 8 shows the system workflow with three different users; the player, teams, and organizer. The organizer manages the tournament, view the team that enters the tournament and generate the matchmaking bracket via PSO and lastly submits the tournament result. For the team, they can view their profile and participate any tournament that has been registered in the system. For the player, they may only view and update their profile.

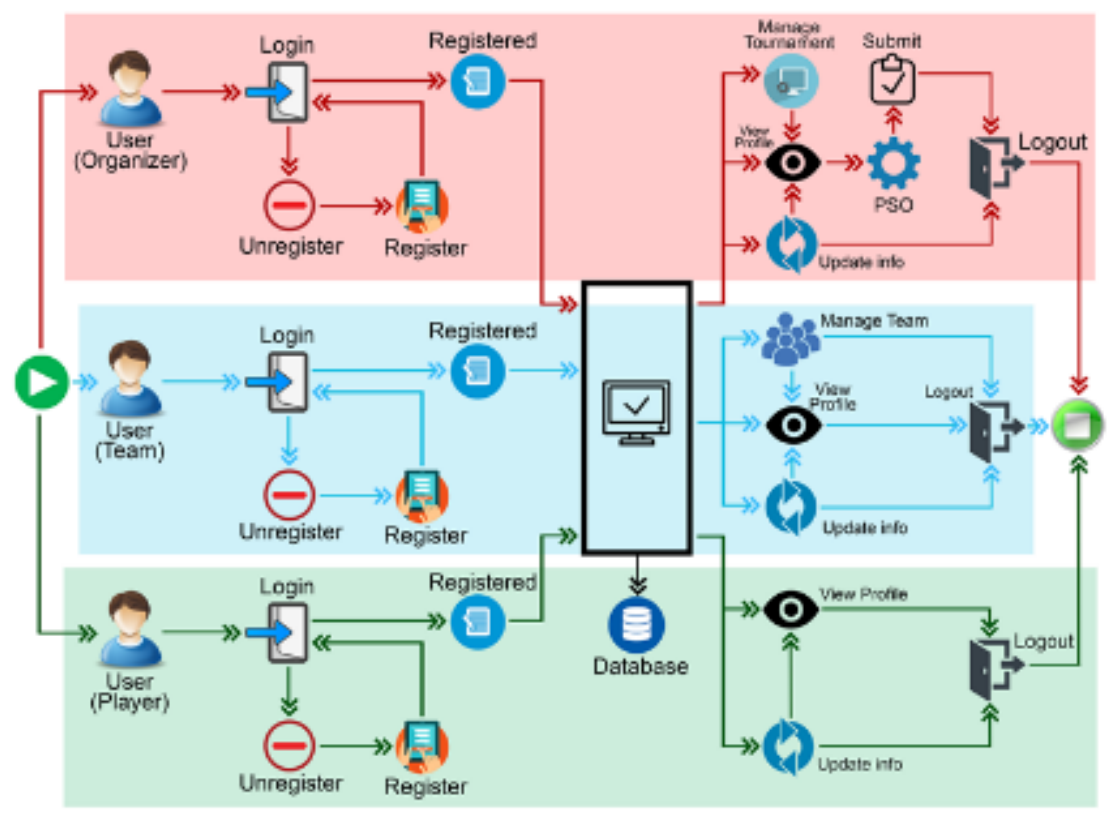

Figure 8. System Workflow

\subsection{Interface Web-based System}

Figure 9 shows the home page for the system named as Speed Paintball (SP). It consists of 3 types of user level which is organizer, team and player. The systematic implementation of BI using PSO been developed and tested through the functionality and convergence test. Figure 10 and Figure 11 shows the player registration page interface and player profile page whereas Figure 12 is the user interface of PSO implementation for dynamic matchmaking team.

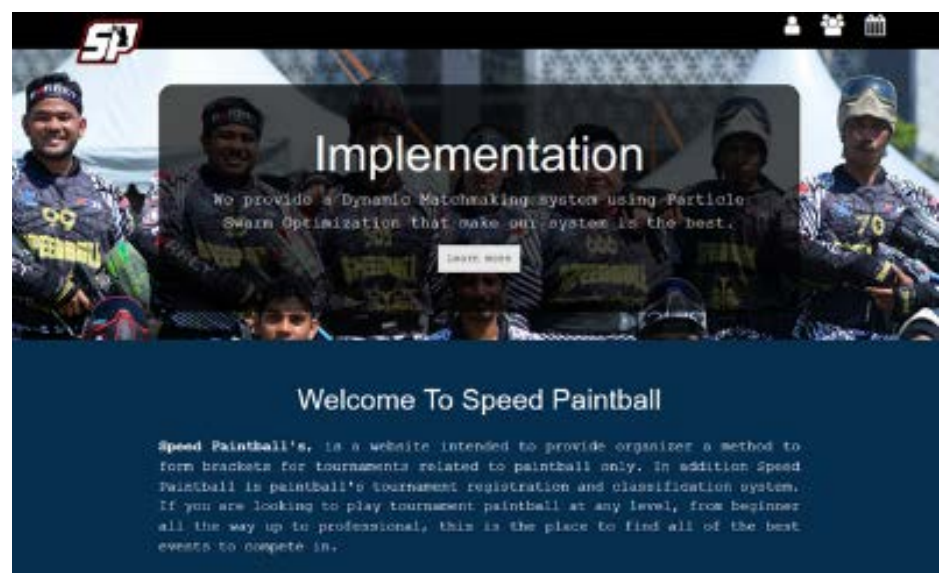

Figure 9. Speed Paintball Home Page 


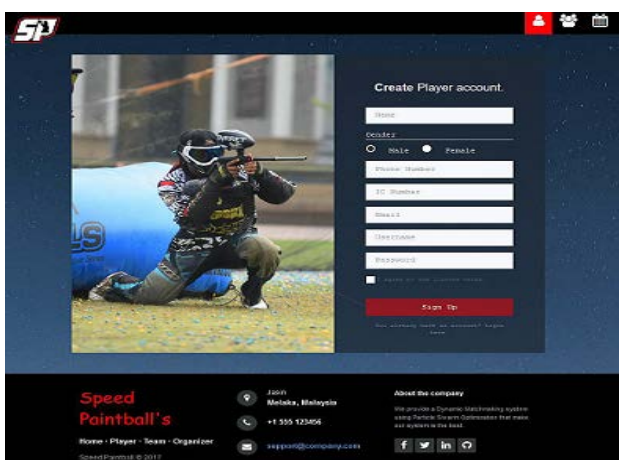

Figure 10. Player Registration Page

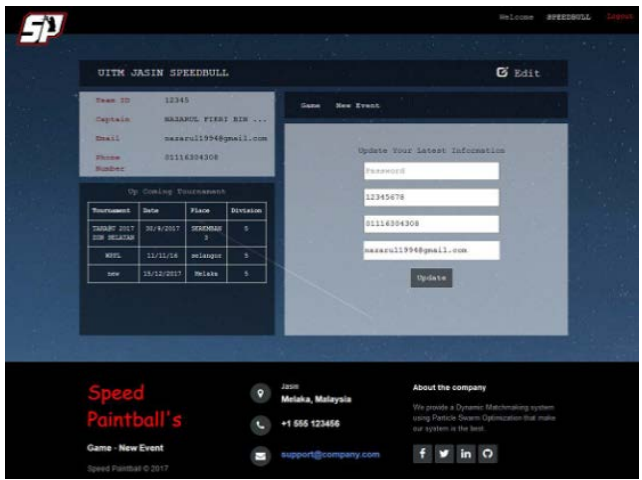

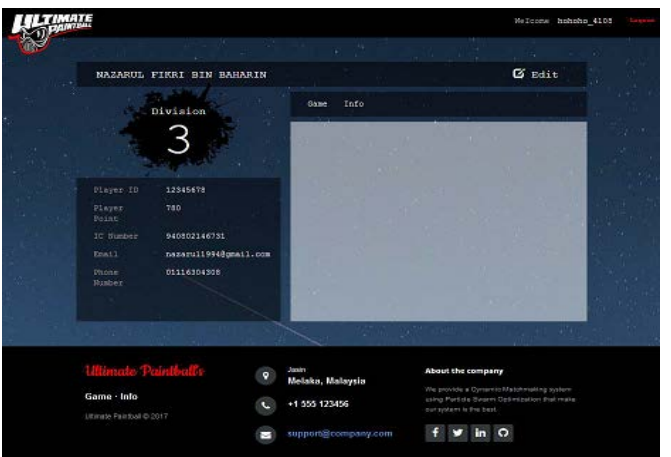

Figure 11. Player Profile Page

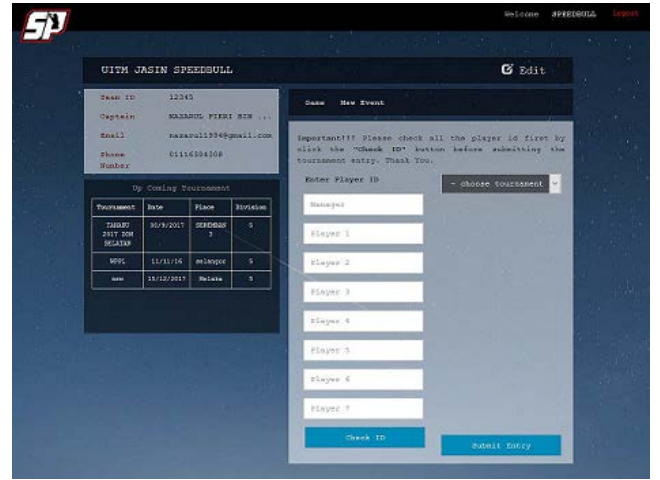

Figure 12. User interface of PSO Implementation

\section{RESULTS AND ANALYSIS}

Convergence testing is conducted to test the reliability of the PSO algorithm to generate a tournament bracket. It been tested using number of teams that enter the tournament as particle size. Thus, the particle size for the testing was 16. There were 3 difference size of populations; 100, 1000 and 10,000. The convergence result on the number of an epoch can be observed as in Figure 13.

The first test for 100 population and it started to converge at epoch 29-59 with the fitness value 47412. For the 1000 and 10,000 population, the fitness value is almost the same with an average value of 49198 and both of it converge at epoch 29-59. From the result, it can be advocated that the algorithm randomly converges regardless of the number of particles being employed in the population. This also suggest that population of 1000 particles are the way to go as further increasing the number of population to 10,000 does not further improve the final solution's fitness value. This indicated that the global optima matchmaking bracket can be obtained by employing 1000 to 10,000 population. Utilizing a small population of candidate of solution such as 100 population may cause the algorithm to be trapped in local optima.

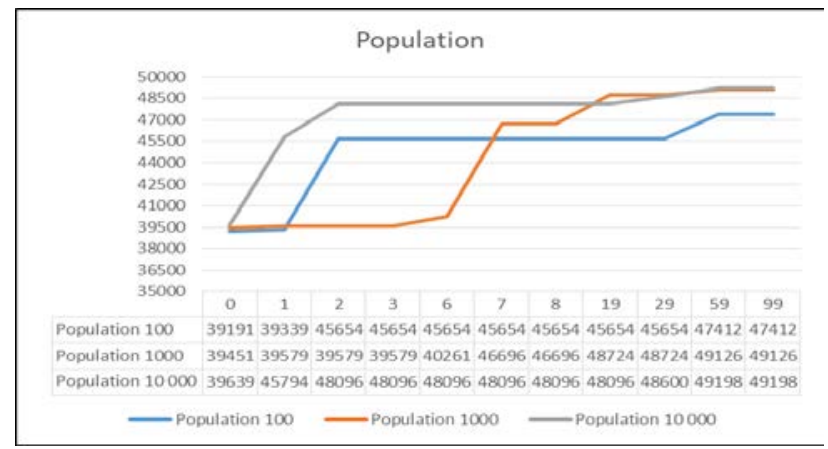

Figure 13. Convergence Test on Epoch 


\section{CONCLUSION}

This paper presents an idea of applying BI for paintball tournament matchmaking using using PSO algorithm to overcome the manual recording in current practise. The effectiveness of the PSO been proven through the convergence test on epoch towards 3 different population and the speed was consistent. Through the web-based system, it able to create the tournament bracket easily and balance them according to the strength and experience of the participants. Nevertheless, this algorithm can be further improved by employing several other tournament formats such as double elimination bracket and round-robin matchmaking bracket.

\section{ACKNOWLEDGEMENT}

This research was supported by Universiti Teknologi MARA, Malaysia through the under iRAGS Grant 2015, Project Code: 600 -RMI /DANA5/3/IRAG5 (3/2015).

\section{REFERENCES}

[1] Salima El Fadili, Firdaos Gmira. Competitive Intelligence: Leaven of a New Managerial Device for Decision Support. Indonesian Journal of Electrical Engineering. 2015; 16(1): 167-175.

[2] Davidson, S. U.S. Patent No. 6,251,033. Washington, DC: U.S. Patent and Trademark Office. 2001.

[3] Shafer, G. S. U.S. Patent No. 6,848,538. Washington, DC: U.S. Patent and Trademark Office. 2005.

[4] Somov, A., Sachidananda, V., Passerone, R. A Self-powered Module with Localization and Tracking System for Paintball. International Workshop on Self-Organizing Systems. 2008; 182-193. Springer Berlin Heidelberg.

[5] Hamdan, N. S., Yusof, A. An Examination of Sport Tourists' Profiles and Motives as for Visiting Langkawi. Middle-East Journal of Scientific Research. 2014; 19(19): 161-165.

[6] Sajjad A., Ehsan T. Using Particle Swarm Optimization, Genetic Algorithm,Honey Bee Mating Optimization and Shuffle Frog Leaping Algorithm for Solving OPF Problem with their Comparison. Indonesian Journal of Electrical Engineering. 2015; 15(3): 445-451.

[7] Kaiyou L, Changjiu P. Complex Optimization Problems Using Highly Efficient Particle Swarm Optimizer. TELKOMNIKA. 2014; 12(4): 1023-1030.

[8] Jamian JJ, Mustafa MW, Mokhlis H, Baharudin MA. Implimentation of Evolutionary Particle Swarm Optimization in Distributed Generation Sizing. International Journal of Electrical and Computer Engineering. 2012; 2(1): 137146.

[9] Pandey, S., Wu, L., Guru, S. M., Buyya, R. A Particle Swarm Optimization Based Heuristic for Scheduling Workflow Applications in Cloud Computing Environments. 24th I EEE International Conference on Advanced Information Networking and Applications. 2010; 400-407.

[10] Goh CK, Tan KC, Liu DS, Chiam SC. A Competitive and Cooperative Co-Evolutionary Approach to MultiObjective Particle Swarm Optimization Algorithm Design. European Journal of Operational Research. 2010; 202(1): 42-54. 